\title{
Design criteria for sediment transport in sewers based on self-cleansing concept
}

\author{
Isa EBTEHAJ ${ }^{1}$, Hossein BONAKDARI ${ }^{\ddagger 1}$, Ali SHARIFI ${ }^{2}$ \\ ( ${ }^{1}$ Department of Civil Engineering, Razi University, Kermanshah 67149-67346, Iran) \\ ( ${ }^{2}$ Department of Statistics, Razi University, Kermanshah 67149-67346, Iran) \\ E-mail: isa.ebtehaj@yahoo.com; bonakdari@yahoo.com; a.sharifi67@yahoo.com \\ Received Apr. 18, 2013; Revision accepted Nov. 4, 2013; Crosschecked Oct. 30, 2014
}

\begin{abstract}
This study of bed-load transport was undertaken on the basis of laboratory data in two states, i.e., limit of deposition and deposited bed, by using new design criteria, whereby, compared to earlier similar studies, fewer parameters were considered, yet with almost the same or in some cases an even greater level of accuracy. The modified criterion in the new design for transport in the limit of deposition was using only three dimensionless parameters, i.e., Froude number, volumetric concentration of sediment, and relative size of the grain. But the new design criterion applied to the deposited bed case used four dimensionless parameters, i.e., three parameters used for the preliminary case besides the relative thickness of sedimentation. Compared with other known relationships in sediment transport, the produced equations introduced here yield better results than previous studies. With the lessened number of parameters, the results are much easier to obtain.
\end{abstract}

Key words: Deposited bed, Bed-load, Limit of deposition, Sediment, Sewers

doi: $10.1631 /$ jzus.A1300135

Document code: A

CLC number: TU992

\section{Introduction}

The need to revamp sewer conduits to collect and safely discharge wastewater has been felt for some time. One extant problem in almost all sewer systems is the deposition of suspended solids, as bedload, at different sections. The long-term deposit of sediments in wastewater systems increases the risk of their transformation and ultimately their consolidation and cementation. In particular, the permanent deposits on the pipe bed during dry seasons cause changes in the cross section such as roughness that affects the velocity distribution and consequently the distribution of the boundary shear stress. Thus, deposits affect the sediment carrying capacity and the hydraulic resistance of the wastewater conduit.

The wastewater system must convey the existing flow in the network under different hydraulic conditions

\footnotetext{
Corresponding author

(C) Zhejiang University and Springer-Verlag Berlin Heidelberg 2014
}

of the plan period. The wastewater collection system must be as free as possible of any deposits. The flow in the wastewater collection and conveyance systems is a free surface and these networks are generally designed and calculated for the estimated ultimate contributory population. In the initial years there will be an expected shortage of flow while the subscribers connect to the network. Moreover, the design of a combined wastewater system must allow for the collection of both wastewater and the surface runoffs. During dry seasons, water levels decrease and the flow rate in the sewers slows down. Therefore, these systems always face the problem of sediment deposition.

Based on the minimum velocity or minimum shear stress at a specified depth of flow or period, two simple criteria, which are generally used as source, have been defined in different countries for estimations in preventing sedimentation at different flow sections under the non-deposition conditions (Ashley et al., 2004). In the USA the minimum velocity must be 0.60 and $0.90 \mathrm{~m} / \mathrm{s}$ for foul and storm sewer types, 
respectively; in France the values are $0.30-0.60 \mathrm{~m} / \mathrm{s}$; in the UK the values must be 0.75 and $1 \mathrm{~m} / \mathrm{s}$ for storm and combined sewers, respectively; and the European standard, EN-752-4 (CEN, 1997), gives a key value of $0.70 \mathrm{~m} / \mathrm{s}$ at least once a day. For the shear stress, the values vary over a wide range that are, for example, $2-4 \mathrm{~N} / \mathrm{m}^{2}$ in Norway, $1-1.5 \mathrm{~N} / \mathrm{m}^{2}$ in Sweden, $2.50 \mathrm{~N} / \mathrm{m}^{2}$ in Germany, and $6.20 \mathrm{~N} / \mathrm{m}^{2}$ in the UK. There is no recommended value for this parameter in France. Ashley et al. (2004) pointed out that American civil engineers' professional rules give minimum values varying from 1.3 to $12.6 \mathrm{~N} / \mathrm{m}^{2}$. Many previous studies have shown that a single value of minimum velocity or shear stress is not adequate to be used for determining the self-cleansing conditions in pipes of different size, roughness, and gradient for the whole range of sediment characteristics and flow conditions found in sewers. Therefore, to design the proper self-cleansing velocity, different parameters, such as concentration and size of sediments, depth or hydraulic radius of the flow, and roughness and diameter of the pipe, should be considered to allow the designer to obtain the minimum velocity according to regional conditions.

Extensive theoretical analyses and experimental work on sediment transport of non-cohesive sediments were carried out in channels by different researchers. Novak and Nalluri (1975) divided the parameters that affect the sediment transport in circular and rectangular canals into two groups, those of transport and flow. They expressed their proposed equation as the relationship between the transport and flow parameters. May (1982) also carried out studies at the limit of deposition in smooth pipes with full and part full flows where the transport was in the form of a bed-load. He developed a theoretical bed-load transport model that is based on forces acting on individual sediment particles transported at the limit of deposition. Mayerle (1988) studied the limit of deposition at part-full flow conditions in a smooth pipe and in two rectangular channels. The rectangular channels were tested for both smooth and rough bed conditions. Loveless (1992) presented a theoretical model for the transport of bed-load at the limit of deposition based on the forces acting on a single particle. He was somehow trying to improve May (1982)'s relationship to underline the importance of the effective transport width at the limit of deposition, as raised by Ackers (1984). Nalluri et al. (1994) carried out an extensive experimental investigation of sediment transport in channels and developed empirical equations with high correlation coefficients. By using Alvarez-Hernandez (1990) and El-Zaemey (1991)'s data, Nalluri et al. (1997) made an assessment of the existing sediment transport equations. Nalluri and Ota (2000) developed a new model for the sediment transport at the limit of deposition criterion based on physical concepts. Similarly, Ota and Nalluri (2003) suggested a relationship for large sewers which is applicable to the limit of deposition criterion over rigid beds. This model leads to more economical solutions than the previously developed best fit deterministic models. May (2003) developed a design method on sediment movement in horizontal or nearly horizontal pipes. Almedeij and Almohsen (2010) offered some remarks on the Camp's criterion and proposed a lower limit of flow strengths above which the method may warrant the development of a more efficient storm sewer system. Enfinger and Mitchell (2010) used the tractive force method to design sewers with self-cleansing conditions based on a critical shear stress. This method can be extended from the design of new sewers to the evaluation of existing sewers under actual conditions. Using geneexpression programming (GEP), Ghani and Azamathulla (2011) presented an approach for modeling the functional relationships of sediment transport in sewer pipe systems. Ibro and Larsen (2011) proposed a method, based on a finite difference scheme to model the sediment transport with special focus on the self-cleansing problem. Azamathulla et al. (2012) used a multiple regression model and an adaptive neuro-fuzzy inference system (ANFIS) to predict the functional relationships of sediment transport in sewer pipe systems, which showed that the ANFIS approach gives more satisfactory results compared to previous methods. Almedeij (2012) suggested a self-cleansing design procedure for rectangular sewers based on the sediment transport theory. Ota and Perrusquía (2013) studied sediment transport at the limit of deposition in sewers, which suggested a modified dimensionless bed shear stress equation. Bong et al. (2013) confirmed the existing equations for incipient motion for a rigid rectangular channel and proposed a new equation by incorporating the sediment deposit thickness. Ebtehaj and Bonakdari 
(2013) predicted the sediment transport in pipes by using the artificial neural network.

The previous studies have introduced different parameters, such as the mean sediment size $(d)$, the relative density of sediment $(s)$, the dimensionless sediment size $\left(D_{\mathrm{gr}}\right)$, the hydraulic radius $(R)$, the friction factor with sediment $\left(\lambda_{\mathrm{s}}\right)$, cross sectional area of the flow $(A)$, settling velocity of particles $\left(W_{\mathrm{s}}\right)$, and the sediment volumetric concentration $\left(C_{\mathrm{V}}\right)$, for obtaining the minimum required velocity to prevent sedimentation. By expanding their introduced equations, most researchers have presented them in two sections: on the left side of the equation they have used the obtained Froude number, $F r=V /\left[g d\left(s^{-1}\right)\right]^{0.5}$, and on the right the dimensionless parameters obtained from dimensional analysis. This study follows the general trend of equations proposed also by previous researchers, with this difference, however, that the impact of parameters on sediment transport has been reduced. The sediment transport is reviewed in two states of non-deposited bed-load transport and the deposited bed-load transport. For the non-deposited bed-load transport, the effects of the parameters of obtained Froude number $F r, C_{\mathrm{V}}$, and the relative size of particles $(d / R$ or $d / y)$ are considered. Moreover, to review the sediment transport in the deposited bed-load state, in addition to the above three, the impact of relative depth of deposits $\left(y_{\mathrm{s}} / D\right)$ has also been taken into consideration. The predicted values by proposed equations are in good agreement with the experimental data measurements.

\section{Self-cleansing design concept}

The self-cleansing process in the wastewater system must establish a balance between the amount of sediment and the rate of erosion during the sediment transport and, in a specific period of time, minimize the combined costs of construction, operation, and maintenance of the system (Butler et al., 2003). The most important aspect of these requirements is that if a minimum amount of sediment allows the design of the wastewater system to become more economical, there is no need for the sewer conduits to stay completely free of deposits. May et al. (1996) showed that the presence of a deposited bed allows the flow to enhance the sediment transport capacity in a form of a bed-load, i.e., in being related to the width of the deposited bed, the sediment transport is then greater than when the flow is in the form of a narrow band along the pipe length of the bed in the non-deposition state. The flow leaves a greater impact on the sediment transport while compensating for the loss of velocity caused by the roughness of the bed surface. Finally, the increase in depth (and width) of the deposited bed and the increased capacity of sediment transport may both be in balance with the inlet sediment load preventing further sedimentation. Therefore, the self-cleansing design concept for non-cohesive, homogenous sediments can be attributed to the movement of the input of the sediment on the bed of the sewer or on the ground of nondeposition of sediments. The concept of nondeposition design was amended through the application of a greater number of parameters, classified in two groups which are described below.

\subsection{Design criteria for non-deposited sediment transport}

The non-deposition sediment transport has two forms, the suspended load and the bed-load. To use the criteria for non-deposition sediment transport, data such as mean sediment size, relative density of sediment, sediment volumetric concentration, and depth of flow are required to propose an equation for the rate of the sediment transport as bed-load or suspended load and the state of transport should be specified before the existing self-cleansing equations can be used. Given the studies conducted by May et al. (1996), if $U_{*}>0.75 W_{\mathrm{s}}$, where $U_{*}$ is the shear velocity, the sediment transport will be in the form of suspended load, otherwise the transport mode will be in the form of bed-load, with $U *$ defined as

$$
U_{*}=V \sqrt{\lambda / 8},
$$

where $V$ is the self-cleansing velocity and $\lambda$ is defined as

$$
\lambda=8 g n_{\mathrm{m}}^{2} / R^{1 / 3}
$$

where $\lambda$ is the friction coefficient of the bed, $g$ the gravity acceleration, $n_{\mathrm{m}}$ the Manning roughness coefficient, and $R$ the hydraulic radius.

May et al. (1996) have proposed the following equation for a bed-load transport: 


$$
\begin{gathered}
C_{\mathrm{V}}=3.03 \times 10^{-2} \frac{D^{2}}{A}\left(\frac{d}{D}\right)^{0.6}\left(1-\frac{V_{\mathrm{t}}}{V}\right)^{4}\left[\frac{V^{2}}{g D(s-1)}\right]^{1.5}, \\
V_{\mathrm{t}}=0.125[g(s-1) d]^{0.5}\left(\frac{y}{d}\right)^{0.47},
\end{gathered}
$$

where $D$ is the pipe diameter, $y$ the depth of flow, and $V_{\mathrm{t}}$ the threshold velocity of movement. According to Ackers et al. (1996), Eq. (3) is the best relationship proposed for the sediment transport in a bed-load state. It is controlled by the data of 332 different tests and offers the best results. The conditions of the tests are: pipe diameter of 77 to $450 \mathrm{~mm}$; sediment size of 160 to $8300 \mu \mathrm{m}$; relative depth of flow $(y / D)$ of 0.16 to 1 ; flow velocity of 0.24 to $1.5 \mathrm{~m} / \mathrm{s}$; and the sediment volumetric concentration $C_{\mathrm{V}}$ of $2.13 \times 10^{-4}$ to $2.11 \times 10^{-3}$.

Vongvisessomjai et al. (2010) conducted several experiments in the limit of deposition and, by using parameters which have the most influence for sediment transport in the limit of deposition, presented the following equation that employs regression analysis:

$$
\begin{aligned}
& \frac{V}{\sqrt{g(s-1) d}}=4.31 C_{\mathrm{V}}^{0.226}\left(\frac{d}{R}\right)^{-0.616}, \\
& \frac{V}{\sqrt{g(s-1) d}}=3.57 C_{\mathrm{V}}^{0.21}\left(\frac{d}{y}\right)^{-0.542} .
\end{aligned}
$$

To present the equations proposed in this study, the set of data provided by Ghani (1993) has been applied. This study's equation will also be reviewed for the non-deposition state using Ghani (1993)'s equation in the following form:

$$
\begin{aligned}
\frac{V}{\sqrt{g(s-1) d}} & =3.08 C_{\mathrm{v}}^{0.21} D_{\mathrm{gr}}^{-0.09}\left(\frac{R}{d}\right)^{0.53} \lambda_{\mathrm{s}}^{-0.21}, \\
\lambda_{\mathrm{s}} & =1.13 \lambda_{0}^{0.98} C_{\mathrm{V}}^{0.02} D_{\mathrm{gr}}^{0.01}
\end{aligned}
$$

where $\lambda_{0}$ is the clear water friction factor.

\subsection{Design criteria for limited deposit sediment transport}

A bed deposit occurs when a flow in which the sediment is transported in the form of bed-load joins the flow in the part full conduit while the velocity is not at a level to prevent deposition. This increases the bed resistance causing the depth of flow to increase and the velocity to decrease. Intuitively, it might be assumed that the drop in velocity is the cause of the reduction in the capacity of the sediment transport in the flow, which would lead to a greater deposit and eventually an obstruction. However, laboratory observations (May, 1993) showed that the presence of a deposited bed allows the flow to have a greater sediment transport capacity in the form of a bed-load. This is due to the level of the sediment transport being related to the width of the deposited bed, which can be much greater than the narrow flow of sediment that occurs along the length of the pipe bed at the level of sedimentation. Finally, an increase in the depth (and width) of the deposited bed and the increased capacity of the sediment transport may be in balance with the inlet sediment load and prevent further sedimentation. Therefore, a small amount of sedimentation may be useful at some sections of the movement. It should be emphasized that this occurs only in part full pipe, because in designing the part full flow, the increase in the integrity of bed roughness and the reduction in the discharge capacity can become a problem, although an added hydraulic gradient can be applied. Nalluri and Ghani (1996) showed that the presence of a sediment deposit at limited depth on the bed of the sewer reduces the slope needed to design for all diameters of the used pipes. The limited depth of the deposit considers the amount of the sediment and the specifications of the flow, and shows the actual conditions of the flow in the wastewater conduit. The use of this limited depth criterion requires an accurate performance and strict maintenance of the system, as the condition is quite close to critical. Nalluri and Ghani (1996) suggested further that if wastewater systems of $1 \mathrm{~m}$ deep or greater were to be designed as a deposited bed, they could be designed in an efficient manner, so for the sediment transport in pipes of over $1 \mathrm{~m}$ or more in diameter they used the equations (Ghani, 1993) shown below:

$$
\begin{aligned}
& \frac{V}{\sqrt{g d(s-1)}}=1.18 C_{\mathrm{v}}^{0.16}\left(\frac{W_{\mathrm{b}}}{y}\right)^{-0.18}\left(\frac{d}{D}\right)^{-0.34} \lambda_{\mathrm{s}}^{-0.31}, \\
& \lambda_{\mathrm{s}}=0.0014 C_{\mathrm{V}}^{-0.04}\left(\frac{W_{\mathrm{b}}}{y}\right)^{0.34}\left(\frac{R}{d}\right)^{0.24} D_{\mathrm{gr}}^{0.54},
\end{aligned}
$$

where $D_{\mathrm{gr}}=d\left[g(s-1) / v^{2}\right]^{1 / 3}$ is the size of dimensionless grains, $W_{\mathrm{b}}$ is the width of deposited bed, and $v$ is the kinematic viscosity of fluid. 


\section{Data collection}

In this research a combination of the lab test results by Ghani (1993) and Vongvisessomjai et al. (2010) were used. Using pipes with three sizes of 154 , 305 , and $450 \mathrm{~mm}$ in diameter and $20.5 \mathrm{~m}$ in length, Ghani (1993) conducted his tests in two states, nondeposition and loose deposited beds. While all three sizes were utilized for the rigid bed tests, he used only the $305-\mathrm{mm}$ pipe for the border roughness test. $\mathrm{He}$ also used a $405-\mathrm{mm}$ pipe for the loose bed tests. Vongvisessomjai et al. (2010) conducted their tests on pipes in two sizes of 100 and $150 \mathrm{~mm}$ in diameter and $16 \mathrm{~m}$ in length. They employed two sections to measure the flow, one at a distance of $4.5 \mathrm{~m}$ upstream and the other at the distance of $5.5 \mathrm{~m}$ downstream. These two points were $6 \mathrm{~m}$ apart. In each section, the velocities were measured at the flow surface, middle depth, and near bottom, and their mean average was taken as the average velocity. For the air/water phase of the flow, the Manning coefficient of roughness $n$ was equal to 0.0125 . Vongvisessomjai et al. (2010)'s tests were conducted in a non-deposited bed state.

To validate the accuracy of the results presented in this study, Ota and Nalluri (1999)'s data were used for the limit of deposition, and Ota et al. (1999)'s data were used for the deposited bed. For the purpose of their tests at the limit of deposition, Ota and Nalluri (1999) used six different dimensions of $d$ (ranging from $0.71 \mathrm{~mm}$ to $5.61 \mathrm{~mm}$ ), and conducted 24 tests in total. Moreover, to test the impact of granulation on the sediment transport, they conducted 20 further experiments using five different ranges of roughness of sediment with an average diameter of $d=2 \mathrm{~mm}$. Ota et al. (1999) conducted their tests on a deposited bed at the Chalmers University of Technology-Sweden, using pipes of $225 \mathrm{~mm}$ in diameter and $25 \mathrm{~m}$ in length The slope of the pipes used was 0.00315 , roughness $k=0.24 \mathrm{~mm}$ and the Manning coefficient of roughness $n$ around 0.01 .

\section{Methodology}

In the circular cross section, the non-deposition state parameters, such as gravity acceleration $g$, pipe diameter $D$, relative density of sediment $s\left(=\rho_{\mathrm{s}} / \rho\right)$, depth of flow $y$, hydraulic radius $R$, and sediment volumetric concentration $C_{\mathrm{V}}$, have the greatest effects on sediment transport and, for a deposition state, besides the previously mentioned parameters, the relative depth of sediment deposit $\left(y_{\mathrm{s}} / D\right)$ has the greatest effect on sediment transport, where $y_{\mathrm{s}}$ is the thickness of sediment bed. By using dimensional analysis, Eqs. (11) and (12), for non-deposited bedload transport and for sediment transport in deposited bed state, respectively, can explain the relationship between these parameters with the self-cleansing velocity as follows:

$$
\begin{gathered}
F r=\frac{V}{\sqrt{g d(s-1)}}=f\left(\frac{d}{y} \text { or } \frac{d}{R}, C_{\mathrm{v}}\right), \\
F r=\frac{V}{\sqrt{g d(s-1)}}=f\left(\frac{d}{y} \text { or } \frac{d}{R}, C_{\mathrm{v}}, \frac{y_{\mathrm{s}}}{D}\right) .
\end{gathered}
$$

\section{Results and discussion}

The two given criteria were derived as semiexperimental equations from the values of Froude number $F r$, the sediment volumetric concentration $C_{\mathrm{V}}$, and the relative size of particles $(d / R$ or $d / y)$. The precision of the devised non-deposited design criteria in this study was reviewed, then compared with the criteria for transport of May et al. (1996) for bed-load and with the deposited bed criteria proposed by Ghani (1993). The results of the comparison between the equations proposed in this study and the extant previous equations are presented herein, using the criteria for root mean square of error (RMSE) and the mean absolute relative error (MARE), as defined below:

$$
\begin{aligned}
\text { RMSE } & =\sqrt{\frac{\sum_{i=1}^{n}\left(x_{i}-y_{i}\right)^{2}}{n},} \\
\text { MARE } & =\frac{1}{n} \sum_{i=1}^{n} \frac{\left|x_{i}-y_{i}\right|}{x_{i}} .
\end{aligned}
$$

Since criteria, such as the minimum square of error or the absolute value of error, do not offer simultaneous comparisons of the average and variance of the models, the Akaike information criterion (AIC) was used to compare the proposed equation to the equations obtained by the previous studies (Ghani, 1993; May et al., 1996; Vongvisessomjai et al., 2010). 
It is defined as

$$
\mathrm{AIC}=n \cdot \lg \left[\frac{1}{n} \sum_{i=1}^{n}\left(x_{i}-y_{i}\right)^{2}\right]+2 k
$$

where $x_{i}$ and $y_{i}$ represent observed and calculated $F r$, respectively, $n$ the number of data, and $k$ the number of estimated parameters included in the model. The AIC is a measure of the relative goodness of the fit of a statistical model. AIC values provide a means for a model selection, and describe a tradeoff between bias and variance in model construction or, loosely speaking, between the accuracy and the complexity of the model.

\subsection{Non-deposited bed-load}

To devise the non-deposited design criteria, the sediment volumetric concentration $C_{\mathrm{V}}$ and other relevant parameters are presented as non-dimensional groups. The essential equation in the non-dimensional form was obtained in a manner similar to

$$
F r=\frac{V}{\sqrt{g d(s-1)}}=a C_{\mathrm{V}}^{b}\left(\frac{d}{R} \text { or } \frac{d}{y}\right)^{c} .
$$

To obtain the coefficients ( $a, b$, and $c$ ) of Eq. (16), using the non-linear regression and the digital analysis in MINITAB software, the best equations that the Froude number presents with the sediment volumetric concentration $C_{\mathrm{V}}$ and $(d / R)$ or $(d / y)$ at different conditions are expressed as follows:

$$
\begin{aligned}
& F r=4.49 C_{\mathrm{v}}^{0.21}\left(\frac{d}{R}\right)^{-0.54}, \\
& F r=3.59 C_{\mathrm{v}}^{0.22}\left(\frac{d}{y}\right)^{-0.51} .
\end{aligned}
$$

The same margin of error of $1 \%$ was obtained with a confidence interval of $99 \%$ differing in the ranges of $(-0.314,0.385)$ and $(-0.394,0.545)$ for Eqs. (17) and (18), respectively. This means that in $99 \%$ of the repeated tests the difference between the fitted and the actual amount of the test data were within the mentioned range. Furthermore, a theoretical test on the equality of two vectors (the tested and the fitted samples) was conducted using the $t$-student test, resulting in $p$-value $=0.785$ and 0.665 for Eqs. (17) and (18), respectively. As this value is much higher than the margin of error of $1 \%$, these two vectors can be considered to be comparatively equal.

For statistical significance, testing the $p$-value gives the probability of obtaining a test statistic at least as extreme as one actually observed, assuming that the null hypothesis is true. One often 'rejects the null hypothesis' when the $p$-value is less than the predetermined significance level, while its value being 0.05 or 0.01 indicates that it is highly unlikely to be any observable result under the null hypothesis.

Fig. 1 shows the generated Froude numbers yielded from Eqs. (17) and (18) versus the lab results presented by Ghani (1993). The $x$ axis shows the left side of Eqs. (17) and (18), and the $y$ axis their right side. It is observable from Fig. 1 that both equations yield relatively good results almost at all points. Except at the maximum Froude number (with a relative error of 6\%), Eq. (17), presented for the situation that considers $d / R$, returns relatively equal results compared to those obtained in the laboratory at the points remaining. Moreover, Eq. (18), presented for the situation that considers $d / y$, displays good results compared to those obtained in the laboratory. At low Froude numbers, the results obtained from Eq. (17) are better than those obtained with Eq. (18), but as the Froude number increases, despite the good accuracy of both equations, the results of Eq. (17) conform better with the laboratory data. The equations presented have been evaluated by using the RMSE and MARE. The outcomes of the evaluations show that Eq. (17) depending on the $d / R$ with RMSE $=0.21$ and MARE $=$ 0.09 , returns better results in comparison to those

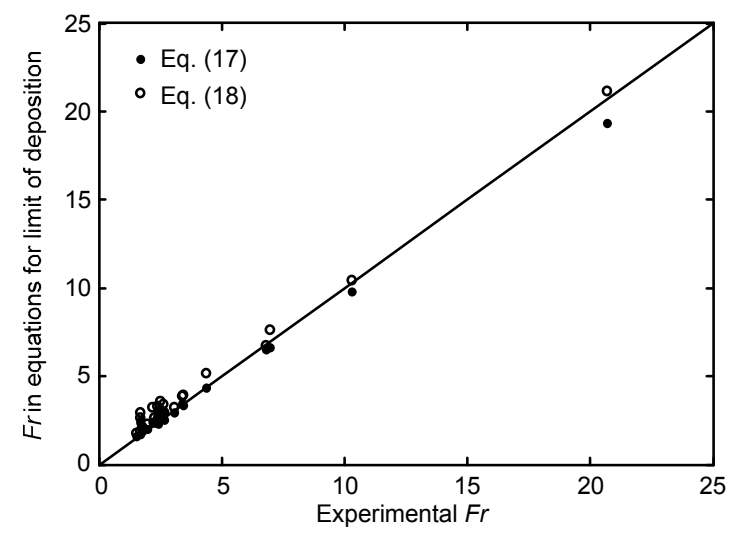

Fig. 1 Validation of the proposed Eqs. (17) and (18) with selected data (Ghani, 1993) 
obtained with Eq. (18) using $d / y$ with $\mathrm{RMSE}=0.35$ and MARE $=0.2$.

Fig. 2 evaluates proposed Eq. (17) against Eq. (5) by Vongvisessomjai et al. (2010), and Eq. (3) by May et al. (1996), recognized by Ackers et al. (1996) as the best one for predicting the velocity of sediment transport in sewers at the limit of deposition. Based on Fig. 2, all three equations show good results at $F r<5$, despite the fact that Eq. (17)'s results show greater accuracy than the other two, showing compatibility with the laboratory results at all points. For $F r>5$, Eq. (17) remains accurate and in the worst case, for the Froude number of around 20, it has a relative error of $6 \%$, while Eqs. (3) and (5) exhibit a similar trend, i.e., their errors increase with the Froude number. But at the highest Froude number, May et al. (1996)'s Eqs. (3) and Vongvisessomjai et al. (2010)'s Eqs. (5) show a relative error of $48 \%$. The results of the evaluation of Eqs. (3), (5), and (17) prove that Eq. (17) with $\mathrm{RMSE}=0.21$ and $\mathrm{MARE}=0.09$, due to its lower AIC, has greater accuracy than Eq. (5) with RMSE $=0.51$ and MARE $=0.21$ and Eq. (3) with $\mathrm{RMSE}=0.69$ and MARE=3.7 (Fig. 2). The AIC results show that Eq. (17) with $\mathrm{AIC}=-12.85$ has greater accuracy compared to what Eq. (3) has with $\mathrm{AIC}=$ 26.64 or Eq. (5) with $\mathrm{AIC}=23.61$.

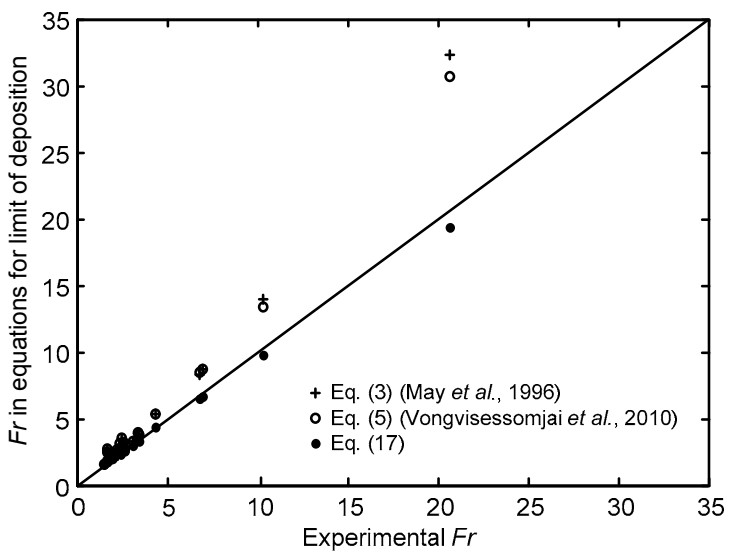

Fig. 2 Comparison of Eq. (17) for $d / R$ with the equations of May et al. (1996) and Vongvisessomjai et al. (2010)

Fig. 3 is an evaluation of Eq. (18) vs. Eq. (6) presented by Vongvisessomjai et al. (2010) and Eq. (3) by May et al. (1996). As Fig. 3 demonstrates, the accumulation of data in all three equations occurs at $F r<5$. In this range, despite the relative appropriateness of all three results, Eq. (6) has an increasing trend at $F r<10$, similar to, but with more errors, than the other two Eqs. (3) and (18). At $F r>5$ the results of Eq. (18) still conform to the results of lab tests while they are higher for the other two equations. At this higher range of Froude numbers, contrary to the lower range of $<5$, Eq. (3), with a relative error of $60 \%$, shows weaker results than Eq. (6). As shown clearly in Fig. 3, Eq. (18), with RMSE=0.24 and MARE= 0.15, has greater accuracy than Eqs. (6) and (3), with the evaluation criteria $\mathrm{RMSE}=0.26$ and MARE $=0.31$, and $\mathrm{RMSE}=0.69$ and MARE $=3.7$, respectively. To further confirm the superiority of Eq. (18) over Eqs. (3) and (6), the AIC criterion was applied. Since Eq. (18) has $\mathrm{AIC}=-4.43$ against Eqs. (6) and (3) with $\mathrm{AIC}=20.72$ and $\mathrm{AIC}=26.64$, respectively, its accuracy is higher than that of the other two.

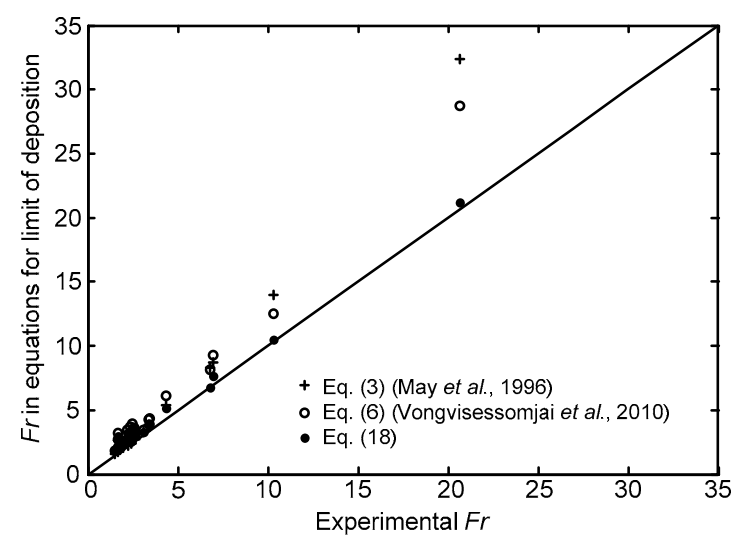

Fig. 3 Comparison of Eq. (18) for $d / y$ with the equations of May et al. (1996) and Vongvisessomjai et al. (2010)

Table 1 shows the evaluation criteria MARE, RMSE, and AIC for Eqs. (5) and (6) of Vongvisessomjai et al. (2010), and Eq. (3) of May et al. (1996), as well as Eqs. (17) and (18) proposed in this study for the limit of deposition case. Both Eqs. (17) and (18) yield better values of evaluation criteria than Eqs. (5) and (6). Given the fact that compared with Eq. (3), which is claimed to be the best equation for sediment transport at the limit of deposition, and Vongvisessomjai et al. (2010)'s equations, the proposed Eq. (16) yields better results, and we can recommend its application to predict sediment transport in sewers at the limit of deposition. 
Table 1 Criteria used to evaluate limit of deposition equations

\begin{tabular}{lccc}
\hline \multicolumn{1}{c}{ Equation } & MARE & RMSE & AIC \\
\hline $\begin{array}{l}\text { Eq. (3) (May et al., 1996) } \\
\text { Eq. (5) (Vongvisessomjai }\end{array}$ & 0.7 & 0.69 & 26.64 \\
$\quad$ et al., 2010) & & 0.51 & 23.61 \\
$\begin{array}{l}\text { Eq. (6) (Vongvisessomjai } \\
\quad \text { et al., 2010) }\end{array}$ & 0.31 & 0.26 & 20.72 \\
$\begin{array}{l}\text { Eq. (17) } \\
\text { Eq. (18) }\end{array}$ & 0.09 & 0.21 & -12.85 \\
\hline
\end{tabular}

According to Table 1, by the validation criteria, Eq. (17) yields the best results for the limit of deposition. To go beyond reasonable doubt and to evaluate Eq. (17) with other sets of data that were not used to obtain it, the applicable lab results of Ota and Nalluri (1999) were correlated with its results.

Fig. 4 evaluates the accuracy of Eqs. (7) and (17) using Ota and Nalluri (1999)'s sets of lab data. The $x$ axis in Fig. 4 represents the Froude number obtained from the lab results, and the $y$ axis represents the results obtained from the limit of deposition's equations. Compared with the lab results, the highest percentage of the related error for Eqs. (7) and (17) is about $13 \%$ and $9 \%$, respectively, while the lowest is about $1.5 \%$ and $0.5 \%$, respectively. Moreover, the AIC criteria were also used to select the best model. The accuracy results of Eqs. (7) and (17) using the lab data proposed by Ota and Nalluri (1999) show that Eq. (17) with $\mathrm{AIC}=2.54$ returns better results than Eq. (7) with $\mathrm{AIC}=19.37$.

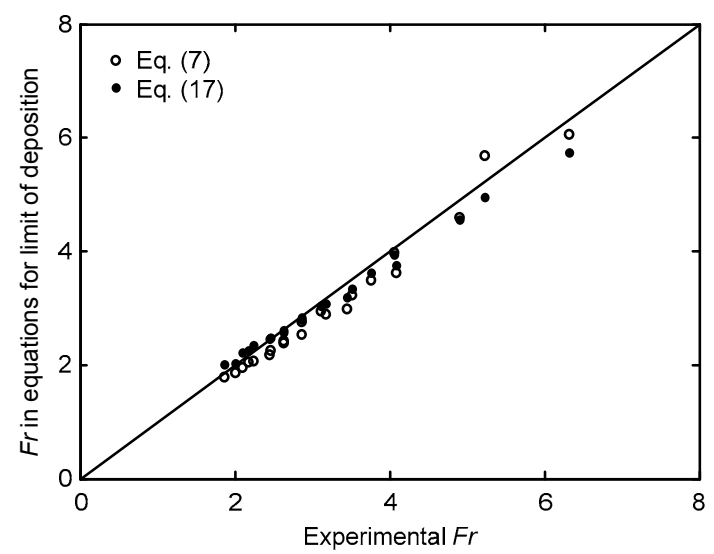

Fig. 4 Evaluation of Eqs. (7) and (17) using Ota and Nalluri (1999)'s sets of data

Moreover, the average error presented by Ota and Nalluri (1999) for all results was about 4\%. While
Eq. (17) presents very good accuracy with Ota and Nalluri (1999)'s sets of data.

\subsection{Bed-load in deposited bed state}

In this state, in addition to the parameters of the concentration of sediments and the relative size of particles, the relative depth of sedimentation is also reviewed as an important parameter in the sediment transport in the deposited state, and Eq. (19) is amended by applying this parameter. To obtain new Eqs. (20) and (21), Eq. (9) proposed by Ghani (1993) is used,

$$
F r=\frac{V}{\sqrt{g d(s-1)}}=a C_{\mathrm{v}}^{b}\left(\frac{d}{R} \text { or } \frac{d}{y}\right)^{c}\left(\frac{y_{\mathrm{s}}}{D}\right)^{d} .
$$

To obtain the coefficients of Eq. (19), using the non-linear regression and digital analysis in MINITAB software, the best equations that have the Froude number in the best result for sediment volumetric concentration $C_{\mathrm{V}}$ and $d / R$ or $d / y$ at different states are expressed as follows:

$$
\begin{aligned}
& F r=2.5 C_{\mathrm{v}}^{0.375}\left(\frac{d}{R}\right)^{-0.766}\left(\frac{y_{\mathrm{s}}}{D}\right)^{-0.258}, \\
& F r=2.8 C_{\mathrm{v}}^{0.335}\left(\frac{d}{y}\right)^{-0.482}\left(\frac{y_{\mathrm{s}}}{D}\right)^{-0.463} .
\end{aligned}
$$

Fig. 5 compares the Froude numbers obtained from Eqs. (20) and (21) and Eq. (9) proposed by Ghani (1993) against the actual ones observed during the experiment. The results of Eqs. (20) and (21) show relatively good results for randomly selected Froude numbers without replacement, to the extent that in almost all the six points they yield results with an error $<5 \%$. This is while the equation proposed by Ghani (1993) in the form of Eq. (9) yields results in the form of the upper limit at all points, i.e., the results at most points are higher than the actual ones.

Based on Table 2, Eqs. (20) and (21) for the deposited bed case yield better results than Ghani (1993)'s equation, with average relative errors of 0.07 and 0.28 , respectively. Moreover, the RMSE of Eqs. (20) and (21) is equal to 0.76, whereas this parameter for Ghani (1993)'s equation is twice that of the proposed equations, i.e., equal to 1.93. Eqs. (20) 
and (21) with AIC values of about 1.83 and 1.87, respectively, yield better results than Ghani (1993)'s equation with $\mathrm{AIC}=14.8$.

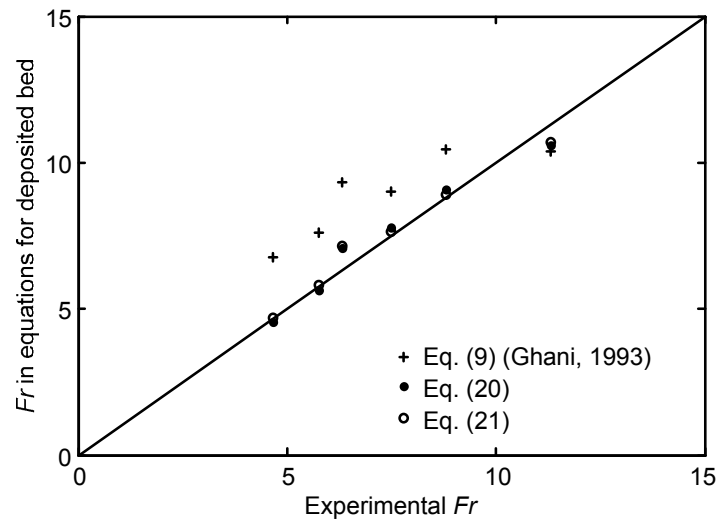

Fig. 5 Comparison of the Froude numbers from Eqs. (9) (Ghani, 1993), (20), and (21) with the experimental Froude numbers

Table 2 Criteria used to evaluate the bed deposit equations

\begin{tabular}{lccc}
\hline \multicolumn{1}{c}{ Equation } & MARE & RMSE & AIC \\
\hline Eq. (9) (Ghani, 1993) & 0.28 & 1.93 & 14.8 \\
Eq. (20) & 0.07 & 0.76 & 1.83 \\
Eq. (21) & 0.07 & 0.76 & 1.87 \\
\hline
\end{tabular}

Table 2 shows that, based on validation criteria, Eq. (20) yields the best results. Therefore, for validating this equation against the set of other data not used in obtaining Eq. (20), the lab results of Ota et al. (1999) were employed. Fig. 6 displays the study for the accuracy of Eq. (20) by using the set of lab data by Ota et al. (1999). The $x$ axis in Fig. 6 represents the Froude numbers obtained from these lab results and the $y$ axis shows those obtained from Eq. (20). It is found that the Froude number obtained from Eq. (20) yields results with relatively good accuracy, as the highest percent of the relative error of this equation is about $11 \%$ and the lowest about $1 \%$ against Ota et al. (1999)'s lab results. Moreover, the average error presented in Table 2 for all results is about $6 \%$, which is almost similar to the MARE value of 0.07 shown in Table 2. Eq. (20) yields results with good accuracy for different sets of data. Therefore, taking this into account for its relative appropriateness, it can be claimed that designs using this equation will have a good percentage of reliability.

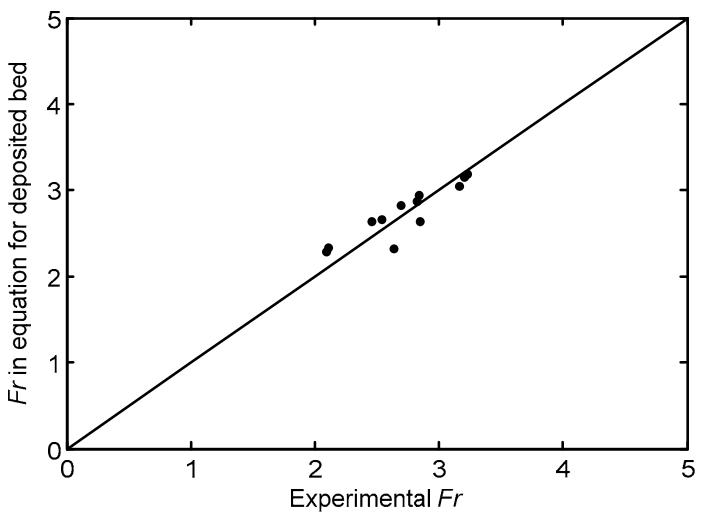

Fig. 6 Evaluation of Eq. (20) using Ota et al. (1999)'s set of data

Based on the evaluation conducted by mathematical reasoning, the devised self-cleansing equations show good consistency with the lab data in explicating the design criteria and for validation. The studies conducted for non-deposited bed-load in two states, the limit of deposition and deposited bed, show a good correlation with the self-cleansing equations of May et al. (1996) and Ghani (1993). In the sediment transport in two states, non-deposited bed-load and deposited bed, the relative size of the particles $(d / R)$ has the highest impact on the self-cleansing velocity. The hydraulic radius $R$ represents the humid perimeter that influences the movement of particles on the channel bed. The sediment volumetric concentration has a greater importance relatively in the bed-load transport of the deposited bed than that of the limit of deposition. For the bed-load, $C_{\mathrm{V}}$ represents the sediment transport occurring in the length of the sewer. If $y_{\mathrm{s}} / D$ is considered in the form of $d / y$, the relative depth of the sediment deposit $y_{\mathrm{s}} / D$ in the deposited bed transport state has a similar effect as the relative size of the grains $(d / y)$. But if it is considered in its form of $d / R$, the effect of the relative size of the particles $d / R$ is twice the relative depth of the sediment deposit $\left(y_{\mathrm{s}} / D\right)$. For both states of the bed-load transport, the relative size of the particles is represented in the two forms of $d / R$ and $d / y$, the errors of the equations becoming quite close to each other. Therefore, the application of either one will make no difference in determining the minimum self-cleansing velocity in the limit of deposition state. However, in the deposited bed state, if $d / R$ is used, the effect of deposition is considered to be less than that of the state when $d / y$ is applied. 


\section{Conclusions}

This study reviews the design criteria for selfcleansing based on the minimum velocity of flow on the bed. Using the lab results proposed by Ghani (1993), this study proposes a number of equations, which can predict the sediment transport in the two states of limit of deposition and deposited bed. The proposed equations have a simpler form than the existing ones. The new equations presented are in two parts, the non-deposited bed-load transport and the bed-load transport with limited deposit. The introduced criteria take into account the parameters that have the highest impact on the sediment carrying capacity and the hydraulic resistance of the wastewater conduit. Despite considering a smaller number of parameters as criteria, the introduced equations have a greater accuracy than other equations, i.e., May et al. (1996) and Vongvisessomjai et al. (2010)'s equations for limit of deposition and Ghani (1993)'s equation for deposited bed. Most parameters in the equations, such as the threshold velocity of movement in the May et al. (1996)'s equation and the friction coefficient of the bed, must be calculated before calculating the self-cleansing velocity. Moreover, the calculation of the parameters in this study is relatively less difficult than the calculation in the previously proposed equations.

\section{Acknowledgements}

The authors would like to express their appreciation to Ellen Vuosalo TAVAKOLI from University of Mazandaran for polishing English.

\section{References}

Ackers, J.C., Butler, D., May, R.W.P., 1996. Design of Sewers to Control Sediment Problems. Construction Industry Research and Information Association, UK.

Ackers, P., 1984. Sediment transport in sewers and the design implications. International Conference on Planning, Construction, Maintenance and Operation of Sewerage Systems, Cranfield, UK, p.215-230.

Almedeij, J., 2012. Rectangular storm sewer design under equal sediment mobility. American Journal of Environmental Sciences, 8(4):376-384. [doi:10.3844/ajessp.2012. 376.384]

Almedeij, J., Almohsen, N., 2010. Remarks on Camp's criterion for self-cleansing storm sewers. Journal of Irrigation and Drainage Engineering, 136(2):145-148. [doi:10. 1061/(ASCE)IR.1943-4774.0000129]

Alvarez-Hernandez, E.M., 1990. The Influence of Cohesion on
Sediment Movement in Channels of Circular CrossSection. PhD Thesis, University of Newcastle upon Tyne, UK.

Ashley, R.M., Bertrand-Krajewski, J.L., Hvitved-Jacobsen, T., et al., 2004. Solids in Sewers: Characteristics, Effects and Control of Sewer Solids and Associated Pollutants. IWA Publishing, London, UK.

Azamathulla, H.M., Ghani, A.A., Fei, S.Y., 2012. ANFISbased approach for predicting sediment transport in clean sewer. Applied Soft Computing, 12(3):1227-1230. [doi:10. 1016/j.asoc.2011.12.003]

Bong, C.H.J., Lau, T.L., Ghani, A.A., 2013. Verification of equations for incipient motion studies for a rigid rectangular channel. Water Science and Technology, 67(2): 395-403. [doi:10.2166/wst.2012.580]

Butler, D., May, R., Ackers, J., 2003. Self-cleansing sewer design based on sediment transport principles. Journal of Hydraulic Engineering, 129(4):276-282. [doi:10.1061/ (ASCE)0733-9429(2003)129:4(276)]

CEN (European Committee for Standardization), 1997. Drain and Sewer System Outside Building: Part 4. Hydraulic Design and Environmental Considerations, EN-752-4. Brussels.

Ebtehaj, I., Bonakdari, H., 2013. Evaluation of sediment transport in sewer using artificial neural network. Engineering Applications of Computational Fluid Mechanics, 7(3):382-392.

El-Zaemey, A.K., 1991. Sediment Transport over Deposited Beds in Sewers. PhD Thesis, University of Newcastle upon Tyne, UK.

Enfinger, K.L., Mitchell, P.S., 2010. Scattergraph principles and practice: evaluating self-cleansing in existing sewers using the tractive force method. World Environmental and Water Resources Congress, Providence, Rhode Island, USA, p.4458-4467. [doi:10.1061/41114(371)453]

Ghani, A.A., 1993. Sediment Transport in Sewers. PhD Thesis, University of Newcastle upon Tyne, UK.

Ghani, A.A., Azamathulla, H.M., 2011. Gene-expression programming for sediment transport in sewer pipe systems. Journal of Pipeline Systems Engineering and Practice, 2(3):102-106. [doi:10.1061/(ASCE)PS.1949-1204.0000076]

Ibro, I., Larsen, T., 2011. Modeling of sediment transport and self-cleansing in sea outfalls. International Symposium on Outfall Systems, Mar del Plata, Argentina.

Loveless, J.H., 1992. Sediment Transport in Rigid Boundary Channels with Particular Reference to the Condition of Incipient Deposition. PhD Thesis, University of London, UK.

May, R.W.P., 1982. Sediment Transport in Sewers, Hydraulic Research Station. Technical Report, Report IT 222, Hydraulic Research Ltd.

May, R.W.P., 1993. Sediment Transport in Pipes and Sewers with Deposited Beds. Technical Report, Report SR 320, Hydraulic Research Ltd.

May, R.W.P., 2003. Preventing sediment deposition in inverted sewer siphons. Journal of hydraulic Engineering, 129(4): 
283-290. [doi:10.1061/(ASCE)0733-9429(2003)129:4(283)]

May, R.W.P., Ackers, J.C., Butler, D., et al., 1996. Development of design methodology for self-cleansing sewers. Water Science and Technology, 33(9):195-205. [doi:10. 1016/0273-1223(96)00387-3]

Mayerle, R., 1988. Sediment Transport in Rigid Boundary Channels. PhD Thesis, University of Newcastle upon Tyne, UK.

Nalluri, C., Ghani, A.A., 1996. Design options for selfcleansing storm sewers. Water Science and Technology, 33(9):215-220. [doi:10.1016/0273-1223(96)00389-7]

Nalluri, C., Ota, J.J., 2000. Non-cohesive sediment transport in clean sewers and with small mobile beds. Joint Conference on Water Resource Engineering and Water Resources Planning and Management, Minneapolis, Minnesota, USA, p.1-11. [doi:10.1061/40517(2000)288]

Nalluri, C., Ghani, A.A., El-Zaemey, A.K.S., 1994. Sediment transport over deposited beds in sewers. Water Science and Technology, 29(1-2):125-133.

Nalluri, C., El-Zaemey, A.K., Chan, H.L., 1997. Sediment transport over fixed deposited beds in sewers - an appraisal of existing models. Water Science and Technology, 36(8-9):123-128. [doi:10.1016/S0273-1223(97)00609-4]

Novak, P., Nalluri, C., 1975. Sediment transport in smooth fixed bed channels. Journal of Hydraulics Division, 101(HY9):1139-1154.

Ota, J.J, Nalluri, C., 1999. Graded sediment transport at limit deposition in clean pipe channel. 28th International Association for Hydro-Environment Engineering and Research, Graz, Austria.

Ota, J.J, Nalluri, C., 2003. Urban storm sewer design: approach in consideration of sediments. Journal of Hydraulic Engineering, 129(4):291-297. [doi:10.1061/(ASCE)07339429(2003)129:4(291)]

Ota, J.J., Perrusquía, G.S., 2013. Particle velocity and sediment transport at the limit of deposition in sewers. Water Science and Technology, 67(5):959-967. [doi:10.2166/wst. 2013.646]

Ota, J.J., Nalluri, C., Perrusquía, G., 1999. Graded sediment transport - the influence of particle size on sediment transport over deposited loose beds in sewers. 8th International Conference on Urban Storm Drainage, Sydney, Australia, p.626-634.

Vongvisessomjai, N., Tingsanchali, T., Babel, M.S., 2010. Non-deposition design criteria for sewers with part-full flow. Urban Water Journal, 7(1):61-77. [doi:10.1080/ 15730620903242824]

\section{中文概要:}

\section{本文题目：基于自清洁理念的下水道中沉积物运移的设计标准 \\ Design criteria for sediment transport in sewers based on self-cleansing concept}

研究目的：通过比较沉积物运移的不同标准, 经选优得出更高精度的标准。

创新要点: 使用更少的参数和分情况来获得高精度的设计标准。

研究方法: 1. 按状态将下水道中沉积物分成两类: 没有沉淀的沉积物和沉淀的推移质; 2. 利用已有设计标 准的方程，运用非线性回归和 MINITAB 软件，得到不同情况下的最佳方程式；3. 用实验所得 的值对各方程预测值进行验证, 比较各方程式的预测精度。

重要结论: 1. 本文提出的方程式可以预测不同情况下的沉积物运移; 2. 相比于其它标准, 本文提出的方 程式形式简单、所需参数少和参数估计简单, 并且预测精度更高。

关键词组: 沉积床; 推移质; 沉积限制; 沉积物; 下水道 